\title{
Effectiveness of Online Positive Psychology Intervention on Psychological Well-Being Among Undergraduate Students
}

\author{
${\text { Phamornpun } \text { Yurayat }^{1} \& \text { Thapanee Seechaliao }}^{2}$ \\ ${ }^{1}$ Department of Educational Psychology and Guidance, Faculty of Education, Mahasarakham University, \\ Mahasarakham, Thailand \\ ${ }^{2}$ Department of Educational Technology and Communications, Faculty of Education, Mahasarakham University, \\ Mahasarakham, Thailand \\ Correspondence: Thapanee Seechaliao, Department of Educational Technology and Communications, Faculty of \\ Education, Mahasarakham University, Mahasarakham, Thailand, 44000. E-mail: thapanee.see@msu.ac.th
}

Received: May 13, 2021

Accepted: June 16, $2021 \quad$ Online Published: June 24, 2021

doi:10.5539/jel.v10n4p143

URL: https://doi.org/10.5539/jel.v10n4p143

\begin{abstract}
Positive psychology intervention is mediation that aims to promote quality of life and well-being. Current research integrating positive psychology with the Internet is called online positive psychology (OPP) which promotes and prevents mental health problems, improves well-being, and reduces depression. This experimental research aimed 1) to compare the psychological well-being of the experimental group that received online positive psychology intervention in the phase of pre-test, post-test, and follow up and 2) to compare the psychological well-being between the experimental group and the controlled group. The subjects were 24 undergraduate students from Mahasarakham University, Thailand, selected by purposive sampling. Thereafter, the subjects were equally divided into experimental and controlled groups. Measures used in this study were as follows: 1) the online positive psychology intervention to improve psychological well-being and 2) the scale of psychological well-being based on Ryff's psychological well-being. The statistics used in the data analysis were the Friedman Test, Wilcoxon signed-rank test, and the Mann Whitney U Test. The results of the pre-test and the post-test showed that the mean scores of psychological well-being of the experimental group were significantly different at 0.05 levels. Additionally, the mean scores of psychological well-being between the experimental group and the controlled group in the phases of post-test and follow-up were significantly different at 0.05 levels. The online positive psychology intervention was effective in increasing the psychological well-being of undergraduate students.
\end{abstract}

Keywords: psychological well-being, positive psychology intervention, online positive psychology intervention, Thai undergraduate students

\section{Introduction}

\subsection{Background}

Positive psychology was a study based on scientific methods about "Good Life" (Peterson \& Park, 2003). At the outset, positive psychology had three goals: the first was to treat mental illness, the second was to make relatively untroubled people happier, and the third was to study genius and high talent (Seligman, Parks, \& Steen, 2004, p. 1379). However, after World War II, the latter two goals received little attention from educators. Positive psychologists were interested in studying happiness as subjective happiness at the beginning, later on, the theory of well-being was developed and the goals of positive psychology were changed to place more interest in studying well-being (Choochom, 2016). Considerations were classified into two perspectives: hedonic perspectives focusing on happiness and eudaimonic perspectives focusing on flourishing (Tuntivivat, 2017). Positive psychologists defined eudaimonic well-being as a means of flourishing, self-actualization, fully functioning, and/or spiritual growth (Ryan \& Deci, 2008; Seligman, 2011). Eudaimonic well-being led to the structures of a variety of flourishing well-being, such as Ryff's psychological well-being (1989), Seligman's well-being Theory (2011), and Deci and Ryan's Self-determination Theory (2008). Ryff's psychological well-being (1989) defined psychological well-being structures into six components: 1) self-acceptance (positive assessment of self-esteem and life), 2) personal growth, 3) purpose in life, 4) positive relations with others, 5) environmental mastery, and 6) autonomy. 
Positive psychology provides a scientific basis that can be empirically proven and measured. As a result, positive psychology interventions were studied and used to enhance the well-being of individuals. The main objectives were to strengthen positive affect awareness, create self-esteem and individuals' internal needs, enhance abilities to manage life goals with a positive and optimistic approach, and deal positively with suffering and failure (Spitzer, 2017). Diverse positive psychology intervention programs were developed and used in broad research studies including basic concepts of gratitude, forgiveness, savouring, strengths, the meaning of life, and empathy-related. In addition, Seligman, Steen, Park and Peterson (2005) developed a short-term positive psychology program that could be implemented without the supervision of a specialist, consisting of gratitude visit, three good things in life, you at your best, using signature strengths in a new way, and identifying signature strengths. The program effectiveness was found that using signature strengths in a new way led to come up with new approaches for themselves. Participants identified their strengths and creatively applied them to daily life problems. In addition, the participants were committed to at the end of the day, writing down in a journal three good things that happened to them. Positive psychological interventions (PPIs) are therapeutics or interventions that generate treatments to enhance positive feelings, behaviors, or cognitions that effectively increase well-being and reduce depression (Sin \& Lyubomirsky, 2009).

University life is the key stage and the turning point of human development transitioning from adolescence to adulthood (Arnett, 2004). Though this period is known for positive self-development (Evans, Forney, Guido, Patton, \& Renn, 2009), it was also identified as having the highest level of incidence in mental health illnesses (Ibrahim, Kelly, Adams, \& Glazebrook, 2013). The World Health Organization [WHO] (2008) revealed that half of the mental disorder disease that happened among adolescents and young adults in high-income countries were correlated with long-term negative effects on individuals, regarding poor academic performance, (Eisenberg et al., 2009), poor daily living in the later stage of life (Goldman-Mellor et al., 2014; Niederkrotenthaler et al., 2014), and dropping out of university (Ishii et al., 2018). Although universities were ready for effective interventions, some research showed that there were significant therapeutic gaps in university students who experienced mental illness. Indeed, one out of five students received the least suitable treatment (Auerbach et al., 2016). Thus, student support services accessibility was relevant. In addition, in recent years, it has been claimed that the internet could facilitate the search for help and resolve mental health problems in university students more effectively (Davies, Morriss, \& Glazebrook, 2014; Ebert, Cuijpers, Muñoz, \& Baumeister, 2017). Counselors could easily and anonymously provide services via e-mail, chat rooms, webcam, or mobile phone (Morin, 2011) including highly efficient and flexible internet programs (Ebert et al., 2018). In 2011, the UK Royal College of Psychiatrists recommended increasing the readiness of evidence-based internet interventions for university students (Royal College of Psychiatrists, 2011). Further, information from mental health clinics at Sutthavej Hospital, Mahasarakham University, revealed that in the academic year 2015, 331 students at Mahasarakham University were treated at the mental health clinic services, 348 students in the academic year 2016, 781 students in the academic year 2017, 1,205 students in the academic year 2018 and 1,556 students in the academic year 2019 respectively. This data reflected the increasing number of students using mental health services. The most treated diseases in the year 2019 were $60.35 \%$ of depression, $13.41 \%$ of anxiety disorders, and $11.37 \%$ of adjustments (Sirisanokaeo, 2020). In addition, there are a large number of researches showed that psychological well-being was critical to mental health and the meaning of lives of university students where students were expected to become an important force in the development of Thai society. Students were expected to be qualified to power a quality society and live in the regional and global communities with dignity (Subprawong, 2015). The recent research pointed out that students could access the internet easier as the statistics claimed that Thai people owned 52 million social network accounts, which meant $75 \%$ of Thailand's population (DIGITAL, 2020; THAILAND, 2020; Online). Students were defined as the group that most frequently used the internet, at an average of 50 minutes to 10 hours a day (Office of Policy and Strategic Affairs, Electronic Transactions Development Agency, Ministry of Digital Economy and Society, 2020). The development of the internet led to significant changes in human life, including an influence on psychological well-being (Sukmawati et al., 2019). Therefore, modifying the form of online assistance helped university students access the support services easily and rapidly, and it also increased well-being and reduced mental health problems. Researchers then developed online positive psychology interventions to improve the psychological well-being of Mahasarakham University undergraduate students, to encourage students to live happily in the university and to be able to adapt themselves appropriately in both university and daily life.

\subsection{Purpose of the Study}

This research determined whether or not the OPPI was effective in increasing the psychological well-being of undergraduate students at Mahasarakham University. The empirical findings were useful for executives and staff, 
at both faculty and university levels, who have the interest to use this designed online positive psychology intervention to improve psychological well-being for their students. The results of this study answered two specific research questions: 1) to compare the level of psychological well-being of undergraduate students in the experimental group in three phases including pre-experimental, post-experimental, and follow-up, and 2) to study any differences in the psychological well-being between the experimental and the controlled groups.

\section{Method}

\subsection{Research Design}

A randomized controlled trial, 2 (group) $\mathrm{x}$ (time) design was used. The two groups included the online positive psychology intervention and the controlled group. The experiment was conducted online through videoconferences from November 2020 until January 2021, aimed to improve the psychological well-being of Mahasarakham University undergraduate students. Participants completed online assessments at pre-, post-, and 1-month follow-up, to evaluate the pre-intervention outcomes, post-intervention outcomes, and durability of change over time.

\subsection{Participant (Subject) Characteristics}

The samples used in the research were 24 undergraduate students at Mahasarakham University, Thailand, in the academic year 2020, selected by purposive sampling. For the selection of samples, the researchers posted the information about this designed program on the university website to allow interested students to leave their mobile number or social network accounts for the researchers to personally contact them later. As a result, 96 students were willing to engage. Subsequently, the researchers contacted them personally through the given information to ask them to complete a questionnaire concerning the scale of psychological well-being. The criterion for sample selection was students who had achieved mean scores below the 50th percentile score that were chosen to participate in the intervention. Finally, 24 students who passed the mentioned criteria were individually interviewed to clarify the purpose of the research, the benefits, obtain preliminary agreement, and inform them that they could resign from this experiment if they found out that it did not serve their needs or interests. Thereafter, the students were asked to meet at the Psychological Excellence Center, Faculty of Education, Mahasarakham University to fill out the application form and the consent form for the experiment. Afterward, all 24 students were randomly divided into two equal groups: 12 students in the experimental group and the other 12 students in the controlled group. Students in the experimental group conducted an online videoconference intervention once a week, for eight weeks, meanwhile, the students in the controlled group did not receive any special treatment.

Exclusion criteria: Once the participants felt uncomfortable or felt that the research project did not meet their needs, they could leave the research program immediately without any consequences. However, if the students missed any weekly appointments, the researchers still completed the intervention as planned but all data collected from these students were excluded from the analysis.

\subsection{Measures}

\subsubsection{The Online Positive Psychology Intervention}

The research instrument referred to the online activities developed to improve students' psychological well-being. After researching various studies, the researchers determined to focus on the concepts of positive psychology, mindfulness, and techniques and theories of individual counseling that were relevant to the development of psychological well-being based on six components of Ryff's psychological well-Being (1989), regarding self-acceptance, personal growth, purpose in life, positive relations with others, environmental mastery, and autonomy.

This designed online positive psychology intervention contained eight sessions, each session lasted between 45 to 90 minutes depending on individual students (Table 1). The researchers conducted each online session with individual students once a week, totally each student took eight sessions in eight weeks. The online positive psychology intervention was evaluated and verified by three experts. This intervention was suitability in highest level $(M=4.941, \mathrm{SD}=0.235)$ and feasibility in highest level $(M=4.941, \mathrm{SD}=0.235)$ that was highest evaluates' level. It could realistically be conducted in a real situation. After revising this designed intervention based on the experts' recommendations the intervention was tried out with six undergraduate students at Mahasarakham University who acquired compatible characteristics to the samples of the experiment for four weeks. After that, the instrument was revised before conducting the research experiment. 
Table 1. Overview of online positive psychology intervention to improve psychological well-being

\begin{tabular}{ll}
\hline Weeks & Contents of OPPI \\
\hline 1 & $\begin{array}{l}\text { Orientation: The objective of this session was to connect with the samples. The researchers used an Ice-breaking activity } \\
\text { called "who I am" along with basic techniques of individual counseling to build the connection with the samples, to create a } \\
\text { friendly, warm, and trusting atmosphere as mutual acceptance led to familiarity and courage to reveal themselves. }\end{array}$ \\
& $\begin{array}{l}\text { Additionally, the researchers clarified the objectives of this program as well as the benefits, and the roles of researchers and } \\
\text { students, time duration, and channels for participating used in this program. } \\
\text { Objectives: To develop students' psychological well-being regarding self-acceptance using "Strengths Interventions" and } \\
\text { "Strengths Interventions: Current Progress and Future Directions" activities. }\end{array}$ \\
3 & $\begin{array}{l}\text { Objective: To develop students' psychological well-being regarding self-acceptance using the "Three Good Things" activity. } \\
\text { Objectives: To develop students' psychological well-being in terms of environmental mastery and autonomy using } \\
\text { techniques called "Writing three bad memories and distress" and "Overcoming obstacles". }\end{array}$ \\
& $\begin{array}{l}\text { Objectives: To develop students' psychological well-being in terms of positive relations with others, using activities called } \\
\text { "Forgiveness letter", "Gratitude letter", and "Gratitude visit". } \\
\text { Objective: To develop students' psychological well-being in terms of personal growth using "Mindfulness" and } \\
\text { "Self-compassion" activities. }\end{array}$ \\
& $\begin{array}{l}\text { Objectives: To develop students' psychological well-being in terms of life and personal growth using the activity called } \\
\text { "Purpose in life and personal growth" and WDEP techniques of the reality counseling theory. }\end{array}$ \\
& $\begin{array}{l}\text { Objective: To develop students' psychological well-being in terms of autonomy using the activity called "Autonomy: } \\
\text { building my way Enhancement of autonomy". }\end{array}$ \\
\hline
\end{tabular}

\subsubsection{The Scale of Psychological Well-Being}

The scale of psychological well-being used in this study was developed based on Ryff's psychological well-being concept, consisting of six components, 50 items of which were rating scales according to Likert's scale, with 5 levels. The scale was used as the pre-test, the post-test, and the follow-up in the pre-experimental, the post-experimental, and the follow-up phases respectively. The objective of this instrument was to assess the development of students' psychological well-being. This instrument was using the index of item-objective congruence (IOC) measure. The five experts measured and the IOC values ranged from 0.60 to 1.00 that indicated this instrument was suitable for conducting the study. The instrument was pilot tested with 40 students from Mahasarakham University in Thailand. The analyzing item-total correlation by determining Pearson's Product Moment Correlation Coefficient was between $0.200-0.745$, and the reliability tested with a Cronbach's alpha coefficient was 0.940 . The test was conducted in the pre-test, post-test, and follow-up.

\subsection{Ethical Considerations}

This research study was approved by the Human Research Ethics Committee of Mahasarakham University (No. 199/2020, issued on 24 July 2020). All data were kept confidential.

\subsection{Data Collection}

The researchers conducted the experiment based on the OPPI to improve the psychological well-being of Mahasarakham University undergraduate students. The procedures were divided into 4 phases.

\subsubsection{Pre-Experimental Phase}

1) Students were recruited through advertising sent via online networks (e.g., Websites, Facebook, Webpage). Participants self-registered online for the study. Later, the researchers clarified this intervention including objectives, processes, time duration, and benefits. Interested students were requested to fill in their personal information on a Google Form. In addition, the researchers provided some contact channels such as a phone number, email address, and place of work. After the period of application, the researchers contacted the students individually through the given channels to ask them to fill in the scale of psychological well-being.

2) The researchers selected the students for the research project. Students were required to gain an average score of psychological well-being below the 50th percentile score (students who were not qualified with this criterion, the researchers provided them other interventions).

3) The researchers conducted interviews and clarified the objectives of the research and the benefits to individual students. The objective of this interview was also to clarify the preliminary agreement and to inform students that they could leave this research program whenever they had no interest, felt that this research program could not serve what they need, or other personal reasons.

4) Afterwards, the researchers scheduled the appointments for individual students to meet at the Psychological Excellence Center, Faculty of Education to fill out the application form and the consent form. 
5) The researchers randomized to divide students into two groups of 12 students by simple random sampling: the experimental group that would be treated by the designed online intervention and the controlled group that would not be treated with any intervention (including collecting scores of psychological well-being measurements as pre-test scores).

6) The researchers studied student's data in the experimental group regarding the average scores of psychological well-being. Later, the researchers prepared media equipment and communication channels before formulating videoconference interventions.

\subsubsection{Experimental Phase}

The researchers conducted videoconference sessions by using the online positive psychology intervention with individual students in the experimental group. This experimental phase lasted eight weeks, between November 2, 2020, and December 27, 2020.

\subsubsection{Post-Experiment Phase}

After finishing all interventions on December 27, 2020, all students in both the experimental and the controlled groups were asked to complete the scale of psychological well-being, defined as the post-test.

\subsubsection{Follow-up Phase}

All students in both two groups were asked to complete the scale of psychological well-being once again on January 22, 2021, or one month after completing the intervention in December. At this time, the scale of psychological well-being intervention was used as the follow-up.

All phases are presented in Figure 1. 


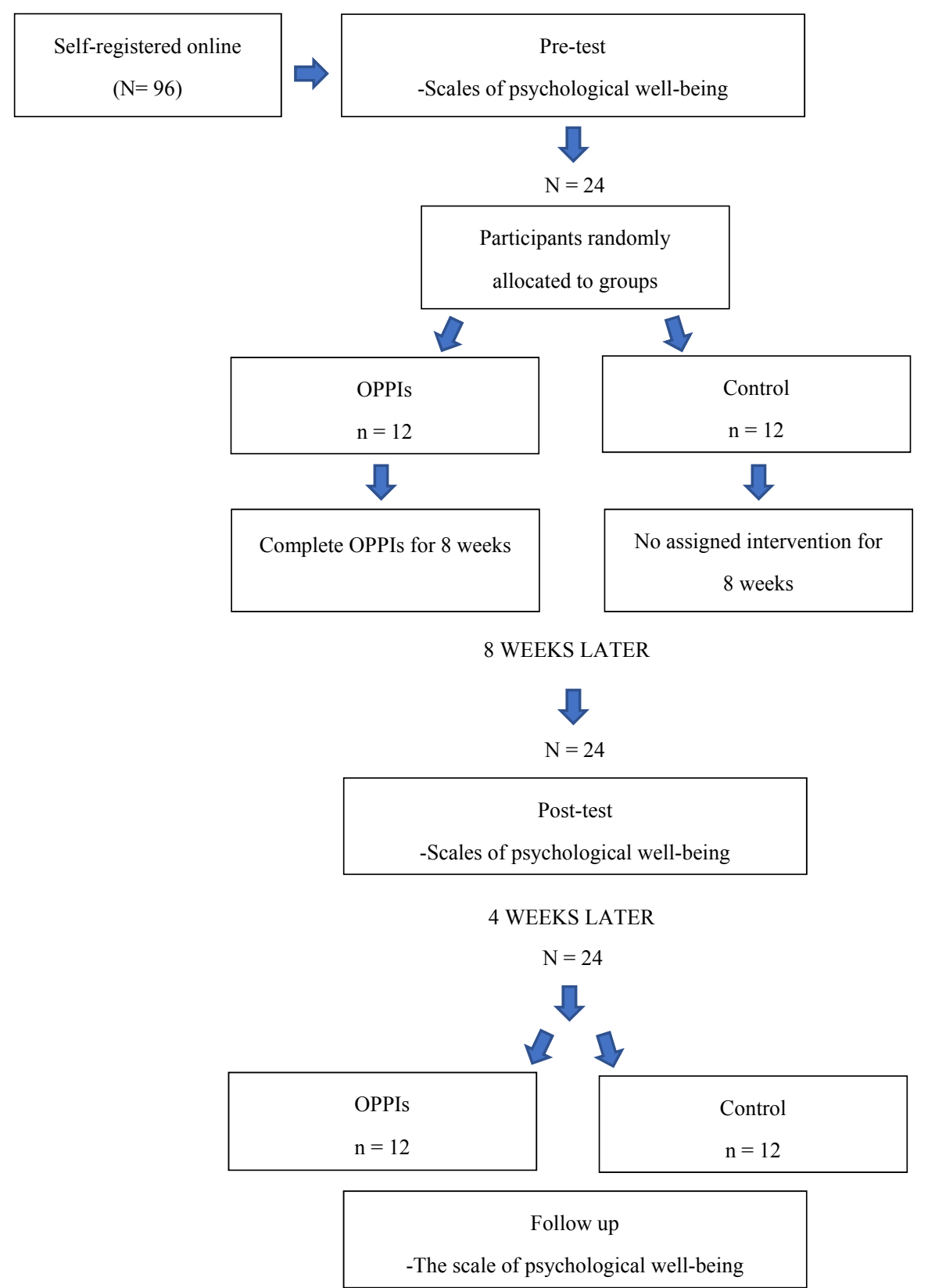

Figure 1. Flowchart of the Procedures

\subsection{Analysis}

2.6.1 The comparison of the mean score of psychological well-being of undergraduate university students in the pest-test, the post-test, and the follow-up based on Friedman Test, if any differences were detected, they would be conducted the Pair Comparison using Wilcoxon signed-rank test.

2.6.2 The comparison of the mean psychological well-being of undergraduate university students between the experimental group and the controlled groups was performed using Mann Whitney U Tests.

\section{Results}

The results indicated that the experimental group had a significantly different psychological well-being with a mean score at the .05 level (Table 2). 
Table 2. Comparison of the mean scores of psychological well-being of the experimental and the controlled groups in the pre-test, the post-test, and the follow-up based on Friedman Test

\begin{tabular}{|c|c|c|c|c|c|c|c|}
\hline \multirow[t]{2}{*}{ Psychological well-being } & \multicolumn{2}{|c|}{ Pre-test } & \multicolumn{2}{|c|}{ Post-test } & \multicolumn{2}{|c|}{ Follow up } & \multirow[t]{2}{*}{ Friedman Test } \\
\hline & $M$ & SD & $M$ & SD & $M$ & SD & \\
\hline Controlled group & 2.126 & 0.299 & 2.125 & 0.126 & 2.091 & 0.176 & 1.217 \\
\hline Experimental group & 2.085 & 0.550 & 3.979 & 0.309 & 3.960 & 0.232 & $18.167^{*}$ \\
\hline
\end{tabular}

Note. ${ }^{*} \mathrm{p}<.05 ; M=$ Mean; S.D. $=$ Standard Deviation.

When differences were found, the data were tested using the Pair Comparison by Wilcoxon signed-rank test. The results showed that the average psychological well-being score of the experimental group comparing between the pre-test and the post-test was significantly different at 0.05 (Table 3 ).

Table 3. Comparison of the mean scores of psychological well-being of the experimental group in the pre-test, the post-test, and the follow up based on Wilcoxon signed rank test

\begin{tabular}{llllll}
\hline & & \multicolumn{2}{l}{ Psychological well-being } & T & \multirow{2}{*}{$p$} \\
\cline { 3 - 4 } & & $M$ & SD & & \multirow{2}{*}{3.059} \\
\hline Experimental group & Pre-test & 2.085 & 0.550 & & $.002 *$ \\
& Post-test & 3.979 & 0.309 & & .530 \\
\cline { 2 - 5 } & Post-test & 3.979 & 0.309 & 0.628 & \\
& Follow up & 3.960 & 0.232 & & \\
\hline
\end{tabular}

Note. ${ }^{*} \mathrm{p}<.05 ; M=$ Mean; S.D. $=$ Standard Deviation; $\mathrm{T}=$ Wilcoxon signed rank test; $p=\mathrm{p}$-value.

The comparison of the psychological well-being between the experimental group and the controlled group in the post-test and the follow-up, the results of the mean scores of psychological well-being showed that the levels of psychological well-being of the two groups were a statistically significant difference at .05 (Table 4).

Table 4. Comparison of psychological well-being of undergraduate students at Mahasarakham University between the experimental group and the controlled group by Mann Whitney U Test

\begin{tabular}{|c|c|c|c|c|c|c|}
\hline \multirow[t]{2}{*}{ Psychological well-being } & \multicolumn{2}{|c|}{ Controlled group } & \multicolumn{2}{|c|}{ Experimental group } & \multirow{2}{*}{$\begin{array}{l}\text { Mann } \\
Z\end{array}$} & \multirow{2}{*}{$\begin{array}{c}\text { Whitney test } \\
p\end{array}$} \\
\hline & $M$ & SD & $M$ & SD & & \\
\hline Pre-test & 2.085 & 0.550 & 2.126 & 0.299 & 0.235 & .814 \\
\hline Post-test & 3.979 & 0.309 & 2.125 & 0.126 & 4.274 & $.000 *$ \\
\hline Follow up & 3.960 & 0.232 & 2.091 & 0.176 & 4.157 & $.000 *$ \\
\hline
\end{tabular}

Note. ${ }^{*} \mathrm{p}<.05 ; M=$ Mean; S.D. $=$ Standard Deviation; $Z=$ Mann Whitney test; $p=$ p-value.

The mean scores of psychological well-being of the experimental and the controlled groups in the pre-test, the post-test, and the follow-up were presented in Figure 2.

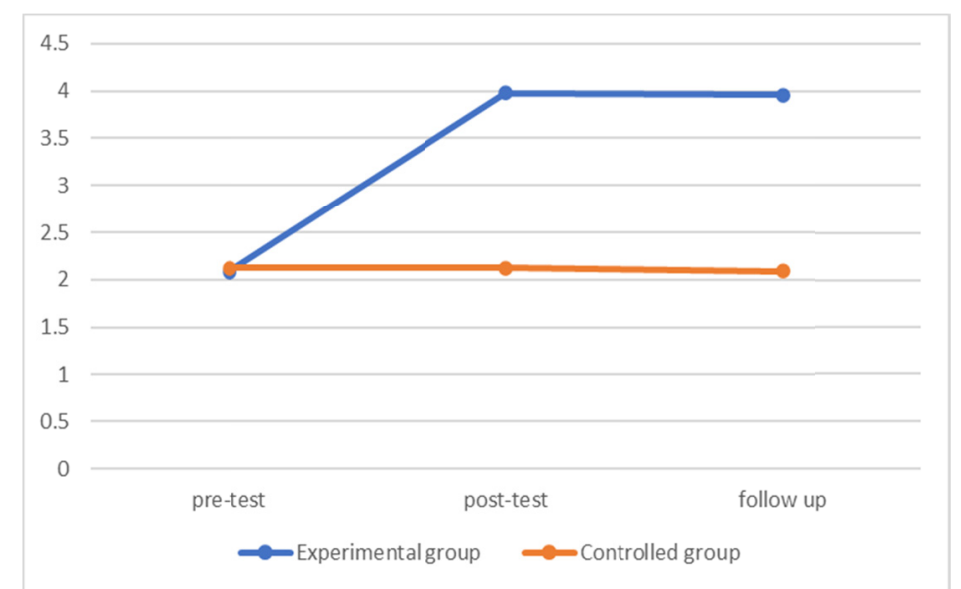

Figure 2. Comparison of the mean scores of psychological well-being in the pre-test, the post-test, and the follow-up between the experimental and the controlled groups 


\section{Discussion}

The results showed that the psychological well-being of the experimental group differed statistically in the pre-test and the post-test after completing the designed online positive psychology intervention. The online positive psychology intervention used in this research referred to the activities created by integrating the concepts of positive psychology of Seligman, Steen, Park and Peterson (2005), Louis and Lopez (2014), Walsh et al. (2018), and Herreroa et al. (2019). Positive psychological interventions (PPIs) refer to activities that were used to enhance the well-being of individuals with the main objectives of developing and raising the awareness of positive feelings and creating self-esteem, internal needs, and abilities. The intervention could facilitate life goals encouraging a positive and optimistic approach and ability to cope with suffering and failure (Spitzer, 2017). The positive psychological interventions were developed in various ways and were used in extensive research studies. They included basic concepts of gratitude, forgiveness, savouring, strengths, the meaning of life, and empathy-related issues. Therefore, positive psychological interventions (PPIs) were therapeutic methods or intervention created to develop positive feelings, behavior, or thinking, that were effective in enhancing well-being, happiness, positive impacts, hope, mental strength, as well as reducing depression and anxiety (Magyar-Moe, Owen, \& Conoley, 2015; Masselink, 2013; Sin \& Lyubomirsky, 2009; Spitzer, 2017). Sakunpong, Ritkumrop and Limwattanachai (2019) mentioned in their study that positive psychological intervention referred to simple activities that anybody could work independently without any help or supports from mental health personnel or a professional psychologist. For example, in 'gratitude writing', a diary in which the writer could express their appreciation towards any good things that happened in everyday life. Moreover, with gratitude writing, the writer could write about their own and other people's strengths, as well as situations around them, to realize those strengths and be able to adjust and use them more effectively.

In addition, the online positive psychology intervention used in this research was developed to serve the concept of mindfulness which meant that mindfulness was a highly productive intervention to relax and reduce stress (Department of Mental Health, Ministry of Public Health, 2015). Several studies have applied mindfulness to guide patients or counselees who acquired emotional problems or well-being deficiency (Brown \& Ryan, 2003; Greeson, 2009; Kabat-Zinn, 2003; Weick \& Putnam, 2006). Further, some techniques and theories of individual counseling were also used, including listening, silence, questioning, reflection feelings, encouragement, clarifying, giving feedback, suggesting, restating, and summarizing. At the same time, the theory of individual counseling was combined, using the WDEP technique (Wants, Directing and Doing, Self-Evaluation, and Planning) developed by Robert Wubbolding (Yurayat, 2020b). This technique was established to encourage people to think through their plans clearly and follow them to achieve the goals. Therefore, following the plan allowed a person to effectively control their own life (Yurayat, 2020a).

Moreover, the online positive psychology intervention of this study included information and communication technology, as well as anonymous online counseling, which was flexible, comfortable, and easier for individuals to access the service. Therefore, online positive psychology intervention provided through the internet was appropriate for the development of positive psychology (Bolier \& Abello, 2014; Ebert et al., 2018; McGonigal, 2011; Munoz, 2010). Much research has pointed out that combining positive psychology with the internet could promote well-being and reduce abnormal symptoms (Mitchell, Stanimirovic, Klein, \& VellaBrodrick, 2009; Parks-Sheiner, 2009; Seligman, Steen, Park, \& Peterson, 2005; Shapira \& Mongrain, 2010). Further, using technology or online counseling was a new concept that is now widely used as it is clear that the effectiveness of the internet facilitated online searching for helping and dealing with mental health problems in university students many counseling activities (e.g., email, chat room, webcam, or mobile phone (Morin, 2011) were conducted through the internet (Davies, Morriss, \& Glazebrook, 2014; Ebert, 2017). More researchers were interested in research concerning online support as it is very advantageous for online counseling (Mitchell, Vella-Brodrick, \& Klein, 2010). Online counseling was easily accessible, anonymous (Ebert et al., 2018), a low-cost intervention (Bolier et al., 2013; Centore \& Milacci, 2008), and could be designed to serve individuals as online counselees (Gander, 2017).

Räsänen et al. (2016), reported a significant improvement in well-being, life satisfaction, and skills in mindfulness in the post-experiment phase. Moreover, in the 12-month follow-up period, the ACT online program was found to be a mix of coach recommendations, face-to-face treatment, and online treatment. It was an effective and well-designed option to promote the well-being of university students. In 2019, Herrero et al. used the internet intervention based on Ryff's psychological well-being model to enhance university students' resilience (Ryff, 1989; Ryff, 2014; Ryff \& Singer, 1996; Ryff et al., 1998). The results showed that the program effectively improved the resilience of university students as they spent a lot of time in the digital world. As activities or tasks were mainly performed through IT communication channels; providing students with 
assistance through the internet was beneficial compared with face-to-face interventions (Christensen \& Hickie, 2010). According to Herrero et al. (2019), it may not be directly related to psychological well-being, but numerous studies found that psychological well-being and resilience were correlated. For example, Sagone and De (2014) found a correlation between resilience and environmental mastery, personal growth, and autonomy. That meant that the more adolescents were able to choose what suited their needs and interests, the more they could strengthen their well-being and autonomy leading to stronger resilience.

In addition, Seligman et al. (2005) presented online positive psychological interventions including "Three Good Things" and "Using Your Strengths in a New Way", that could enhance the level of students' well-being and reduced depression at the same time. Further, six months after conducting this intervention, it was found that the students from the experimental group still continuously strengthened their well-being and had less depression. However, Mongrain and Anselmo-Matthews (2012) claimed in their study that online positive psychological intervention only affected well-being, but not depression. In addition, according to Sakunpong, Ritkumrop, and Limwattanachai (2019), the results showed that students that participated in positive psychology group interventions had higher levels of happiness and social adaptation, both in the post-test and follow-up compared with the scores collected from the pre-test phase. Therefore, it could be concluded that students who received the eight-week online positive psychological intervention had higher levels of psychological well-being in the post-experimental phase than in the pre-experimental phase. In the follow-up phase, students from the experimental group continuously had higher levels of psychological well-being than in the pre-experimental phase. This implies that the designed online positive psychological intervention was enduring and could develop long-term psychological well-being. The findings from the in-depth interview confirmed that online positive psychological interventions such as the Three Goods Things activity could be done easily. Students did not need to spend a lot of time on this, only a few minutes before going to bed, for example. As a result, students felt comfortable doing it even on their difficult days. This showed that students were willing to use some intervention in their daily lives.

For the comparison of the mean scores of psychological well-being between students in the experimental group and the controlled group, the results in the post-test and the follow-up showed that the psychological well-being of students in the experimental group significantly differed from the controlled group. Based on research related to the meta-analysis of positive psychological interventions, it has been revealed that positive psychological interventions could level up happiness and well-being in a wide range of samples, including university students, employees in organizations, hospital patients, etc. (Bolier et al., 2013; Magyar-Moe et al., 2015). In addition, current research studies have integrated positive psychology with the internet. For instance, Bolier et al. (2013) developed an Internet-based self-help intervention, called "Psyfit", which showed that the intervention successfully increased well-being and reduced depression. Psyfit's composition originates from positive psychology (Seligman, Steen, Park, \& Peterson, 2005; Sin \& Lyubomirsky, 2009), mindfulness (Grossman, Niemann, Schmidt, \& Walach, 2004), cognitive behavioral therapy (Riper \& Kramer, 2007) and problem-solving therapy (Cuijpers, 2005). Moreover, numerous studies have proved that combining positive psychology with the internet increased well-being and reduced abnormal symptoms (Mitchell, Stanimirovic, Klein, \& VellaBrodrick, 2009; Parks-Sheiner, 2009; Seligman, Steen, Park, \& Peterson, 2005; Shapira \& Mongrain, 2010). In 2019, Yaghoobi and Nesai Moghadam studied the effects of positive psychological intervention on the psychological well-being of high school girls. The findings found that the experimental group that received the positive psychological intervention had an average score of overall psychological well-being scored by six components that were statistically significantly higher than the controlled group at the 0.001 level. Similarly. Auyeung and Mo (2019) researched the efficacy and mechanisms of self-help online positive psychology intervention to develop eudaimonic well-being that emphasized flourishment and reduced depression of students in China. The results showed that in the post-experiment phase, the experimental group that received the positive psychological intervention had a significantly higher level of well-being than the controlled group. It was additionally revealed that online positive psychology intervention could promote the well-being of university students. In 2014, Jabbari, Shahidi, and Mootabi studied the effects of positive psychological therapy on distorted attitudes and happiness of adolescents, comparing between the experimental group and the controlled group. The results indicated that after participating in an 11-week positive psychological therapy, the level of distorted attitudes of the experimental group decreased significantly but the level of their happiness increased statistically.

This confirmed that positive psychological group therapy could not only reduce distorted attitudes but also increase happiness. Therefore, positive psychological therapy could be used to reduce psychological problems that caused psychological disorders, as well as to improve quality of life. 
Based on the findings, it was concluded that online positive psychology intervention could effectively improve the psychological well-being of the students.

\section{Conclusion}

The findings showed that online positive psychology intervention could enhance the psychological well-being of undergraduate students at Mahasarakham University. It was a form of intervention that could help the students strengthen their happiness, psychological well-being and reduce depression especially when it was performed on the internet. The online channel suited the students' needs because it was comfortable and did not incur travel expenses. Further, students felt comfortable and safe because they did not need to reveal their identity doing it. In addition, university students usually spent a lot of time in the digital world, so it was aligned with their lifestyle.

However, Mahasarakham University should develop the internet network to support more online interventions and other information technology channels such as Mobile Applications, Websites, Virtual Reality, etc. to facilitate and broaden the channel for more interventions related to mental health problems and adaptation of university students for better psychological well-being and a healthy lifestyle.

\section{Acknowledgments}

This research was funded by the research scholarship for the Faculty of Education academic staff, Annual Income Budget 2020 Mahasarakham University.

\section{References}

Arnett, J. J. (2004). Emerging adulthood: The winding road from the late teens through the twenties. New York, NY: Oxford University Press.

Auerbach, R. P., Alonso, J., Axinn, W., Cuijpers, P., Ebert, D., Green, J., ... Bruffaerts, R. (2016). Mental disorders among college students in the World Health Organization World Mental Health Surveys. Psychological Medicine, 46(14), 2955-2970. https://doi.org/10.1017/S0033291716001665

Auyeung, L., \& Mo, P. K. H. (2019). The efficacy and mechanism of online positive psychology intervention (PPI) on improving well-being among Chinese university students: A pilot study of the best possible self (BPS) intervention. Journal of Happiness Studies, 20(8), 2525-2550. https://doi.org/10.1007/s10902-018-0054-4

Bolier, L., \& Abello, K. M. (2014). State of the art and future directions (pp. 286-309). Wiley-Blackwell Handbook. Online Positive Psychological Interventions. Wiley Blackwell: Chichester, West Sussex.

Bolier, L., Haverman, M., Kramer, J., Westerhof, G. J., Riper, H., Walburg, J. A., ... Bohlmeijer, E. (2013). Psyfit, Internet-based intervention to promote mental fitness for mildly depressed adults: Results of a randomized controlled trial. Journal of Medical Internet Research, 15(9), e200, Retrieved from https://www.jmir.org/2013/9/ e200/pdf

Brown, K. W., \& Ryan, R. M. (2003). The benefits of being present: Mindfulness and its role in psychology well-being. Journal of Personality and Social Psychology, 84(4), 822-848. https://doi.org/10.1037/0022-3514.84.4.822

Centore, A. J., \& Milacci, F. (2008). A Study of Mental Health Counselors' Use of and Perspectives on Distance Counseling. Journal of Mental Health Counseling, 30(3). https://doi.org/10.17744/mehc.30.3.q871r684n863u75r

Chester, A., \& Glass, C. A. (2006). Online counselling: A descriptive analysis of therapy services on the Internet. British Journal of Guidance \& Counselling, 34(2), 145-160. https://doi.org/10.1080/03069880600583170

Choochom, O. (2016). The structure of happiness and well-being in positive psychology. Journal of Psychology Kasem Bundit University, 6(2), 1-7.

Christensen, H., \& Hickie, I. B., (2010). Using e-health applications to deliver new mental health services. The Medical Journal of Australia, 192(11), 53-56. https://doi.org/10.5694/j.1326-5377.2010.tb03695.x

Cuijpers, P. (2005). Everything under control-problem solving therapy at the internet. Amsterdam: VU University Amsterdam.

Davies, E. B., Morriss, R., \& Glazebrook, C. (2014). Computer-delivered and web-based interventions to improve depression, anxiety, and psychological well-being of university students: A systematic review and meta-analysis. Journal of Medical Internet Research, 16(5), e130. https://doi.org/10.2196/jmir.3142

Deci, E. L., \& Ryan, R. M. (2008). Hedonia, eudaimonia, and well-being: An introduction. Journal of Happiness 
Studies, 9(1), 1-11. https://doi.org/10.1007/s10902-006-9018-1

Department of Mental Health, Ministry of Public Health. (2015). Mindfulness ... create happiness. Nonthaburi: The Agricultural Cooperative Federation of Thailand.

DIGITAL 2020: THAILAND. (2020). Digital 2020: Global Digital Overview (Online). Retrieved June 3, 2020, from https://datareportal.com/reports/digital-2020-global-digital-overview?utm_source=Reports\&utm_medium= PDF\&utm_campaign=Digital_2020\&utm_content=Dual_Report_Promo_Slide

Ebert, D. D., Cuijpers, P., Muñoz, R. F., \& Baumeister, H. (2017). Prevention of mental health disorders using internet-and mobile-based interventions: A narrative review and recommendations for future research. Frontiers Psychiatry, 8(116), 1-16. https://doi.org/10.3389/fpsyt.2017.00116

Ebert, D. D., Van Daele, T., Nordgreen, T., Karekla, M., Compare, A. T., Zarbo, C., \& Baumeister, H. (2018). Internet and mobile-based psychological interventions: Applications, efficacy, and potential for improving mental health. European Psychologist, 23, 167-187. https://doi.org/10.1027/1016 - 9040/a000318

Eisenberg, D., Golberstein, E., \& Hunt, J. B. (2009). Mental health and academic success in college. The B.E. Journal of Economic Analysis \& Policy, 9(1), 1-40. https://doi.org/10.2202/1935-1682.2191

Evans, N. J., Forney, D. S., Guido, F. M., Patton, L. D., \& Renn, K. A. (2009). Student development in college: Theory, research, and practice (2nd ed.). San Francisco, CA: Jossey-Bass.

Gander, F. (2017). Online positive psychology intervention based on pleasure, engagement, meaning, positive relationships, and accomplishment: Measurement, validation of interventions, and exploration of working mechanisms. https://doi.org/10.5167/uzh-139240

Goldman-Mellor, S. J., Caspi, A., Harrington, H., Hogan, S., Nada-Raja, S., Poulton, R., \& Moffitt, T. E. (2014). Suicide attempt in young people: A signal for long-term health care and social needs. JAMA Psychiatry, 71(2), 119-127. https://doi.org/10.1001/jamapsychiatry.2013.2803

Greeson, J. M. (2009). Mindfulness research update: 2008. Journal of Evidence-Based Integrative Medicine, 14, 10-18. https://doi.org/10.1177/1533210108329862

Grossman, P., Niemann, L., Schmidt, S., \& Walach, H. (2004). Mindfulness-based stress reduction and health benefits: A meta-analysis. Journal of Psychosomatic Research, 57(1), 35-43. https://doi.org/10.1016/S0022-3999(03)00573-7

Herrero, R., Mira, A., Cormo, G., Etchemendy, E., Baños, R., García-Palacios, A., ... Botella, C. (2019). An Internet based intervention for improving resilience and coping strategies in university students: Study protocol for a randomized controlled trial. Internet Interventions, 16, 43-51. https://doi.org/10.1016/j.invent.2018.03.005

Hysenbegasi, A., Hass, S. L., \& Rowland, C. R. (2005). The impact of depression on the academic productivity of university students. Journal of Mental Health Policy and Economics, 8(3), 145-151.

Ibrahim, A. K., Kelly, S. J., Adams, C. E., \& Glazebrook, C. (2013). A systematic review of studies of depression prevalence in university students. Journal of Psychiatric Research, 47(3), 391-400. https://doi.org/10.1016/j.jpsychires.2012.11.015

Ishii, T., Tachikawa, H., Shiratori, Y., Hori, T., Aiba, M., Kuga, K., \& Arai, T. (2018). What kinds of factors affect the academic outcomes of university students with mental disorders? A retrospective study based on medical records. Asian Journal of Psychiatry, 32, 67-72. https://doi.org/10.1016/j.ajp.2017.11.017

Jabbari, M., Shahidi, S. H., \& Mootabi, F. (2014). Effectiveness of group intervention based on positive therapy on dysfunctional attitudes and happiness in adolescent girls. Journal of Clinical Psychology, 6(2), 65-74. https://doi.org/10.22075/JCP.2017.2164

Kabat-Zinn, J. (2003). Mindfulness-based interventions in context: past, present, and future. Clinical Psychology: Science and Practice, 10(2), 144-156. https://doi.org/10.1093/clipsy.bpg016

Kaemkate, W. (2012). Research methodology in behavioral sciences (3rd ed.). Bangkok: Chulalongkorn University.

Kessler, R. C., Foster, C. L., Saunders, W. B., \& Stang, P. E. (1995). Social consequences of psychiatric disorders, I: Educational attainment. The American Journal of Psychiatry, 152(7), 1026-1032. https://doi.org/10.1176/ajp.152.7.1026 
Louis, M. C., \& Lopez, S. J. (2014). Current Progress and Future Directions (p. 66). The Wiley Blackwell handbook of positive psychological interventions.

Magyar-Moe, J. L., Owens, R. L., \& Conoley, C. W. (2015). Positive psychological interventions in counseling: What every counseling psychologist should know. The Counseling Psychologist, 43(4), 508-557. https://doi.org/10.1177/0011000015573776

McGonigal, J. (2011). Reality is broken: Why games make us better and how they can change the world. New York: Penguin Books.

Mertens, D. M. (2014). Research and evaluation in education and psychology: Integrating diversity with quantitative, qualitative, and mixed methods (3rd ed.). California: Sage publications.

Mitchell, J., Stanimirovic, R., Klein, B., \& Vella-Brodrick, D. (2009). A randomized controlled trial of a self guided internet intervention promoting well-being. Computers in Human Behavior, 25(3), 749-760. https://doi.org/10.1016/j.chb.2009.02.003

Mitchell, J., Vella-Brodrick, D., \& Klein, B. (2010). Positive psychology and the Internet: A mental health opportunity. E-Journal of Applied Psychology, 6(2), 30-41. https://doi.org/10.7790/ejap.v6i2.230

Mongrain, M., \& Anselmo-Matthews, T. (2012). Do positive psychology exercises work? A replication of Seligman et al. (2005). Journal of Clinical Psychology, 68, 382-389. https://doi.org/10.1002/jclp.21839

Morin A. (2011). Online Therapy -The Pros and Cons of Internet Psychotherapy (Online). Retrieved July 13, 2011, from http://www.suite101.com/content/online-therapy---the-pros-and-cons-a350798

Munoz, R. F. (2010). Using evidence-based internet interventions to reduce health disparities worldwide. Journal of Medical Internet Research, 12(5), e60. https://doi.org/0.2196/jmir.1463

Niederkrotenthaler, T., Tinghög, P., Alexanderson, K., Dahlin, M., Wang, M., Beckman, K., ... Mittendorfer-Rutz, E. (2014). Future risk of labour market marginalization in young suicide attempters-A population-based prospective cohort study. International Journal of Epidemiology, 43(5), 1520-1530. https://doi.org/10.1093/ije/dyu155

Office of Policy and Strategic Affairs, Electronic Transactions Development Agency, Ministry of Digital Economy and Society. (2020). Thailand internet user behavior 2019. Retrieved from https://www.etda.or.th/th/UsefulResource/publications/Thailand-Internet-User-Behavior-2019_EN.aspx

Parks-Sheiner, A. C. (2009). Positive psychotherapy: Building a model of empirically supported selfhelp. Dissertations available from ProQuest. Paper AAI3363580. https://doi.org/10.1037/e606232010-001

Peterson, C., \& Park, N. (2003). Positive psychology as the evenhanded positive psychologist views it. Psychological Inquiry, 14(2), 143-147. https://doi.org/10.1207/S15327965PLI1402_03

Räsänen, P., Lappalainen, P., Muotka, J., Tolvanen, A., \& Lappalainen, R. (2016). An online guided ACT intervention for enhancing the psychological wellbeing of university students: A randomized controlled clinical trial. Behaviour Research and Therapy, 78, 30-42. https://doi.org/10.1016/j.brat.2016.01.001

Riper, H., \& Kramer, J. (2007). Color Your life-internettherapie for the prevention of depression. Utrecht: Trimbos-instituut; 2007.

Royal College of Psychiatrists. (2011). Mental health of students in higher education. London: Royal College of Psychiatrists.

Ryff, C. D. (1989). Happiness Is Everything, or Is It? Explorations on the Meaning of Psychological Well-Being. Journal of Personality and Social Psychology, 57(6), 1069-1081. https://doi.org/10.1037/0022-3514.57.6.1069

Ryff, C. D. (2014). Psychological well-being revisited: Advances in the science and practice of eudaimonia. Psychotherapy and Psychosomatics, 83, 10-28. https://doi.org/10.1159/000353263

Ryff, C. D., \& Singer, B. (1996). Psychological well-being: Meaning, measurement, and Implications for psychotherapy research. Psychotherapy and Psychosomatics, 65, 14-23. https://doi.org/10.1159/000289026

Ryff, C. D., Singer, B., Love, G. D., \& Essex, M. J. (1998). Resilience in adulthood and later life: Defining features and dynamic processes. In J. Lomranz (Ed.), Handbook of Aging and Mental Health: An Integrative Approach. Plenum Press, New York. https://doi.org/10.1007/978-1-4899-0098-2_4

Sagone, E., \& De Caroli, M. E. (2014). Relationships between psychological well-being and resilience in middle and late adolescents. Procedia-Social and Behavioral Sciences, 141, 881-887. 
https://doi.org/10.1016/j.sbspro.2014.05.154

Sakunpong, N., Ritkumrop, K., \& Limwattanachai, P. (2019). Effects of Positive Psychology Group Intervention on Well-being and Social Adjustment of Secondary Students in Boarding School: A Mixed Methods Approach. Journal of Behavioral Science for Development, 1(11), 35-52.

Seligman, M. E. P. (2011). Flourish: A visionary new understanding of happiness and well-being. New York: Free Press.

Seligman, M. E. P., Parks, A. C., \& Steen, T. A. (2004). A balanced psychology and a full life. Philosophical Transactions of the Royal Society of London. Series B: Biological Sciences, 359, 1379-1381. https://doi:10.1098/rstb.2004.1513

Seligman, M. E. P., Steen, T. A., Park, N., \& Peterson, C. (2005). Positive psychology progress: Empirical validation of interventions. American Psychologist, 60, 410-421. https://doi.org/10.1037/0003-066X.60.5.410

Shapira, L. B., \& Mongrain, M. (2010). The benefits of self-compassion and optimism exercises for individuals vulnerable to depression. The Journal of Positive Psychology, 5(5), 377-389. https://doi.org/10.1080/17439760.2010.516763

Sin, N. L., \& Lyubomirsky, S. (2009). Enhancing well-being and alleviating depressive symptoms with positive psychology interventions: A practice-friendly meta-analysis. Journal of Clinical Psychology, 65, 467-487. https://doi.org/10.1002/jclp.20593

Sirisanokaeo, T. (2020). Report of students' information for mental health clinic services Sutthawet Hospital. Sutthawet Hospital Mahasarakham University.

Spitzer, M. (2017). Effect and Use of Positive psychology intervention in Clinical Practice. A Systematic Literature Review. Retrieved from: https://essay.utwe nte.n1/73117/

Subprawong, K. (2015). Mediating role of self- concept in studying effects of positive thinking and students' backgrounds on psychological well-being. Journal of Research Methodology, 28(1), 49-73.

Sukmawati, I., Ardi, Z., Ifdil, I., \& Zikra, Z. (2019). Development and validation of acceptability of mental-health mobile app survey (AMMS) for android-based online counseling service assessment. Journal of Physics, 1339(1), 012124. IOP Publishing.

Tuntivivat, S. (2017). Positive Psychology: Concept, Development and Challenges for the Future. Journal of Behavioral Science for Development, 9(1), 277-290. Retrieved from https://so02.tci-thaijo.org/index.php/JBSD/article/view/75954

Weick, K. E., \& Putnam, T. (2006). Organizing for mindfulness: Eastern wisdom and Western knowledge. Journal of Management Inquiry, 15(3), 275-287. https://doi.org/10.1177/1056492606291202

World Health Organization [WHO]. (2008). Global tuberculosis control: Surveillance, planning, financing: WHO report 2008. Geneva: World Health Organization. Retrieved from https://apps.who.int/iris/handle/10665/43831

Yaghoobi, A., \& Nesai, M. B. (2019). The effect of positive psychology intervention on the psychological well-being of adolescents. Iranian Journal of Psychiatry and Clinical Psychology, 25(1), 14-25. https://doi.org/10.32598/ijpcp.25.1.14

Yurayat, P. (2020a). Group Counseling: Principles, concepts, and theories (2nd ed.). Mahasarakham: Apichat Publication.

Yurayat, P. (2020b). Group Psychotherapy. Mahasarakham: Apichat Publication.

\section{Copyrights}

Copyright for this article is retained by the author, with first publication rights granted to the journal.

This is an open-access article distributed under the terms and conditions of the Creative Commons Attribution license (http://creativecommons.org/licenses/by/4.0/). 